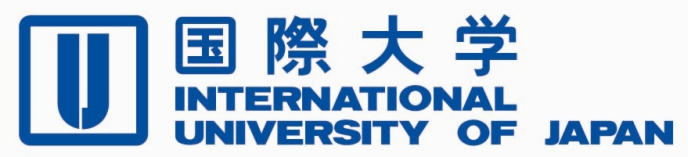

Economics \& Management Series

EMS-2011-09

\title{
Efficiency in a Search and Matching Model with Train- ing Costs
}

\author{
Hiroaki Miyamoto \\ International University of Japan
}

March 2011

IUJ Research Institute

International University of Japan

These working papers are preliminary research documents published by the IUJ research institute. To facilitate prompt distribution, they have not been formally reviewed and edited. They are circulated in order to stimulate discussion and critical comment and may be revised. The views and interpretations expressed in these papers are those of the author(s). It is expected that the working papers will be published in some other form. 


\title{
Efficiency in a Search and Matching Model with Training Costs*
}

\author{
Hiroaki Miyamoto ${ }^{\dagger}$ \\ International University of Japan
}

March 2011

\begin{abstract}
This paper studies the efficiency of the search and matching model with training costs. I incorporate productivity enhancing firm-specific skill training into the search and matching model of Pissarides (2000). I demonstrate that while the decentralized economy can be efficient if training costs are not sunk at the time of wage determination, the decentralized economy is not efficient due to a hold-up problem if training costs are sunk.
\end{abstract}

Keywords: Search and matching model; Efficiency; Training

JEL Classification: E24; J40; J64

${ }^{*}$ I am grateful to Stephen G. Hall and an anonymous referee for very helpful comments and suggestions. I am also grateful to Etienne Lehmann and Yoshimasa Shirai for for their invaluable comments and suggestions. All remaining errors are mine.

${ }^{\dagger}$ Corresponding Address: Hiroaki Miyamoto, International University of Japan, Graduate School of International Relations, 777 Kokusai-cho, Minami Uonuma-shi, Niigata 949-7277 JAPAN. E-mail: hmiyamot@iuj.ac.jp. TEL.:+81-25-779-1464. FAX:+81-25-779-1187 


\section{Introduction}

Training is an important determinant of labor market outcome. Recently, the effects of firm-specific skill training on labor market dynamics have been studied in the literature of the search and matching model (Mortensen, 2000; Higashi, 2002; Miyamoto and Shirai, 2006, Shintoyo, 2007). On the other hand, it is well known that labor market imperfection affects training decisions and results in inefficiencies in them (Malcomson, 1997). These inefficiencies in training decisions affect labor market outcomes and thus the efficiency of an economy. Analyzing the efficiency properties of the search and matching model is interesting and relevant as it can inform us about the degree in which the equilibrium unemployment rate differs from the efficient unemployment rate. Furthermore, studying the efficiency of models with labor market frictions and training costs is important not only from a theoretically point of view but also in quantitative studies where the Hosios (1990) condition is sometimes used. ${ }^{1}$ For example, Pissarides (2009) and Silva and Toledo (2009a, b) calibrate the matching model with training cost by assuming that the Hosios condition holds.

The purpose of this paper is to analyze the efficiency of a labor market with matching frictions and firm-specific skill training. For this purpose, I incorporate productivity enhancing firm-specific skill training into the search and matching model of Pissarides (2000). In the model, a firm can train its employee to increase the productivity of the match. When a firm meets a worker, the firm decides a level of training, incurring training costs that depend on the level of training. Since the investment is specific to the production unit, as Williamson (1975) and Grout (1984) emphasized, the incentives to invest in firm-specific human capital may be reduced when a binding complete contract cannot be written and enforced before costs of specific investment are sunk. Thus, it is crucial to take into account the effect of contract incompleteness on the firm's training decision when the investment decision concerns specific capital. To grasp this, the model also allows for a varying degree of contract incompleteness by assuming that the training cost can be fully, partially or not sunk.

The main result is that the Hosios condition does not necessarily apply to this new

\footnotetext{
${ }^{1}$ In the standard Mortensen-Pissarides search and matching model in which wages are determined by Nash bargaining, the market equilibrium is efficient if the worker's bargaining power equals the elasticity of the matching function with respect to unemployment. This is well known as the Hosios (1990) condition.
} 
environment. It only does so in the case in which training costs are not sunk. If training costs are not sunk, a firm does not suffer from a hold-up problem on its training costs and thus the level of training in the decentralized economy is efficient. In this case, the Hosios condition delivers efficiency in the decentralized economy. On the other hand, if training costs are completely or partially sunk, since not all of the costs are not shared with a worker, a firm reduces investments. This inefficiency can only be prevented by removing all the bargaining power from the worker. However, this depresses wages and creates excessive entry of firms, leading to inefficient equilibrium unemployment rate.

My model is not the first to introduce endogenous training into search and matching models. A number of studies develop a matching model with endogenous training (Mortensen, 2000; Higashi, 2002; Miyamoto and Shirai, 2006). However, they focus on the effect of training on labor market dynamics rather than the efficiency consequences of introducing training to the search and matching model. Boone and de Mooij (2003) and Hungerbuhler (2007) also introduce endogenous training into a matching model and study the effect of tax on the labor market efficiency. While they focus on a static version of static version of a search and matching model, this paper assess the consequences of training costs on labor market outcome in a dynamic search model.

My paper is also related to the literature of the efficiency of a search and matching model with match-specific costs. Cheron (2005) finds that if the fixed match-specific costs are not sunk, the Hosios condition delivers efficiency. In contrast, this paper studies the efficiency of the matching model in which the match-specific costs are endogenously determined, and finds the similar result. Acemoglu and Shimer (1999) also study the efficiency of the search and matching model under the presence of match-specific investments. They demonstrate that there will be inefficiency as long as investment costs are sunk, and inefficiency can only be prevented by removing all the bargaining power from the worker. While a firm makes ex ante investments before matching with a worker in Acemoglu and Shimer (1999), in my model a firm decides the level of investments after matching with a worker. Thus, this study shows that when investment costs are sunk, the timing of investments does not play an important role in this finding. 


\section{The Model}

In this study, I introduce productivity enhancing firm-specific skill training into the model of Pissarides (2000). In the model, a firm can train its employee to increase the productivity of the match. When a firm with a vacant job is matched with a worker, the firm decides a level of training $h$, and incurs the training cost $C(h)$. The cost function satisfies $C^{\prime}(h)>0$ and $C^{\prime \prime}(h)>0$. The equilibrium level of training is denoted by $\tilde{h}$ that an atomistic firm would take as given when choosing its training level. A firm-worker pair with training level $h$ produces the output $p+f(h)$, where $p$ is a general productivity parameter which is common to all producing jobs and the production function $f(h)$ represents the enhanced productivity due to firm-specific skill training given to the matched worker. ${ }^{2}$ The production function $f(h)$ satisfies $f^{\prime}(h)>0, f^{\prime \prime}<0$, and the Inada conditions: $\lim _{h \rightarrow \infty} f^{\prime}(h)=0$ and $\lim _{h \rightarrow 0} f^{\prime}(h)=\infty$.

An economy consisting of a continuum of workers normalized to one and a large number of identical risk-neutral firms. Time is continuous. All agents are infinitely lived and maximize the present discounted value of their income with discount rate $r$.

A firm has only one job that can be either filled or vacant. One job is filled by one worker. A firm can produce output if its job is filled. If a firm does not employ a worker, it posts a vacant job at flow cost $\gamma$ and searches for a worker. A worker can be either employed or unemployed. If a worker is employed, he produces output and earns an endogenous wage but cannot search for other jobs. If he is not employed, he gets a flow utility $z$ from non-market activity and searches for a job. When a firm with a vacant job and an unemployed worker meet and start producing, it is said that job creation takes place. On the other hand, job separation takes place when a filled job separates and stops producing. Separation occurs according to a Poisson process with exogenous arrival rate $s$. When job separation takes place, the worker becomes unemployed, while the firm can either reopen a job as a new vacancy or withdraw from the labor market. ${ }^{3}$ Free entry drives the expected present value of an open vacancy to zero.

The number of successful job matches per unit time is given by the matching function

\footnotetext{
${ }^{2}$ The additive form of the output, $p+f(h)$, is not crucial to results of the paper. For example, I can obtain the similar results by assuming output takes the form $p f(h)$. However, the additive form of the output fits the usual definition of training. Usually, training is considered as a method to improve workers' knowledge and skills. Without training, the workers can still produce but at lower productivity levels.

${ }^{3}$ Note that in equilibrium firms are indifferent between these two options.
} 
$M(u, v)$, where $u$ is the number of unemployed workers and $v$ is the number of vacancies. The matching function $M(u, v)$ is continuous, twice differentiable, increasing in its arguments, and exhibits constant returns to scale. Define $\theta \equiv v / u$ as the tightness of the labor market. The rate at which a firm with a vacancy is matched with a worker per unit of time is $M(u, v) / v=M(1 / \theta, 1) \equiv q(\theta)$. Similarly, the rate at which an unemployed worker is matched with a firm per unit of time is $M(u, v) / u=\theta q(\theta)$. Because the matching function has constant-returns, $q(\theta)$ is decreasing in $\theta$ and $\theta q(\theta)$ is increasing in $\theta$. In the steadystate, the inverse of the transition rates, $1 / q(\theta)$ and $1 / \theta q(\theta)$, are the expected duration of a vacancy and unemployment, respectively. I also make the standard Inada-type assumptions on $M(u, v)$, which ensure that $\lim _{\theta \rightarrow \infty} q(\theta)=0, \lim _{\theta \rightarrow 0} q(\theta)=\infty, \lim _{\theta \rightarrow \infty} \theta q(\theta)=0$, and $\lim _{\theta \rightarrow 0} \theta q(\theta)=\infty$.

The wages are determined through the Nash bargaining between a firm and a worker over the share of expected future joint income, where the worker has bargaining power $\beta$ $\in[0,1)$. It is assumed that, at the wage determination stage, the part of the training cost is considered as a loss in joint income.

I introduce a parameter $\xi \in[0,1]$ that captures the share of training costs which is specific and whose quasi rents cannot be protected by contract. The parameter can be thought of as corresponding to the degree of contract incompleteness. Note that setting $\xi=1$ implies that wages are bargained before the training cost is incurred; while $\xi=0$ implies that wages are bargained after the cost is incurred; i.e., the nature of the cost being sunk or not.

The burden of training costs is affected by contractual incompleteness between the firm and the worker. If a firm and a worker can pre-commit to an enforceable wage contract that determines terms of employment contingent on future evens when they form a match, i.e., the contract is complete, the worker shares the training costs by accepting a lower wage. In this case, training costs are not specific to the production unit, and a hold-up problem does not exist. On the other hand, if complete contracts are not enforceable, the bargain is about the wage only and the training costs are paid by the firm alone and a hold-up problem does exist.

The timing of events and of decisions is as follows: first, when a firm with a vacant job is matched with a worker, the firm decides how much to invest in worker's firm-specific skills. The firm and the worker then bargain the wage. Depends on the degree of contract incompleteness, the part of training costs is taken into account by the firm and the worker 
as a loss in their joint income when they bargain the wage.

Let the value of a vacant job be $V$ and the value of a filled job with training level $h$ be $J(h)$. They are characterized by the following Bellman equations:

$$
r V=-\gamma+q(\theta)[J(h)-V-C(h)]
$$

and

$$
r J(h)=p+f(h)-w(h)+s[V-J(h)] .
$$

I now turn to a worker's side. Let $W(h)$ and $U$ represent the value of an employed worker with training level $h$ and an unemployed worker respectively. Then, the value functions for the workers are given by

$$
r W(h)=w(h)+s[U-W(h)]
$$

and

$$
r U=z+\theta q(\theta)[W(\tilde{h})-U] .
$$

Note that the training level $h$ of an atomistic firm has no impact on the worker's fallback position $U$, which depends on the equilibrium level of training. In other words, $h$ corresponds to the best response by an atomistic firm to the symmetric equilibrium profile of strategies where all firms choose $\tilde{h}$. The equilibrium is indeed defined by $h=\tilde{h}$, but $\tilde{h}$ thereby $U$ are taken as given when the firm chooses its optimal training level.

In equilibrium, all profit opportunities from new jobs are exploited, so that the following free entry condition holds:

$$
V=0
$$

The wages are determined through the Nash bargaining between a firm and a worker over the share of expected future joint income. The wage is determined by the following equation

$$
w(h)=\arg \max (W(h)-U)^{\beta}(J(h)-V-\xi C(h))^{1-\beta} .
$$

Note that when $\xi=1$, the training costs are not sunk when the wage is determined. On the other hand, when $\xi=0$, the training costs are completely sunk and are not considered as a loss in joint income.

The solutions to this optimization problem, $w(h)$, must satisfy the following first-order condition

$$
(1-\beta)(W(h)-U)=\beta(J(h)-V-\xi C(h)) .
$$


I define the total surplus from a match with training level $h$ as $S(h) \equiv J(h)+W(h)-$ $U-\xi C(h)$. Adding (2) and (3) gives

$$
S(h)=\frac{p+f(h)-r U}{r+s}-\xi C(h) .
$$

A firm chooses the training level $h$ to maximize the present-discounted value of its income, $J(h)-V-C(h)$, at the moment of job creation. Since $J(h)=(1-\beta) S(h)+\xi C(h)$ from the wage sharing rule (6), an atomistic firm that takes $U$ and $\tilde{h}$ as given would solve

$$
\max _{h}(1-\beta)\left[\frac{p+f(h)-r U}{r+s}\right]-(1-\beta \xi) C(h),
$$

and the first-order condition is

$$
\frac{(1-\beta) f^{\prime}(\tilde{h})}{r+s}=(1-\beta \xi) C^{\prime}(\tilde{h}) .
$$

Condition (7) states that, in equilibrium, the optimal training level, $h=\tilde{h}$, is such that the marginal cost of training is equal to the expected gain from a marginal increase in training.

By using the value function (4), the free entry condition (5), and the wage sharing rule (6), I have the following total surplus function

$$
S(h)=\frac{p+f(h)-z}{r+s+\theta q(\theta) \beta}-\frac{(r+s) \xi C(h)}{r+s+\theta q(\theta) \beta} .
$$

Making use of (1), (5), and (8), I obtain the equilibrium job creation condition

$$
\frac{\gamma}{q(\theta)}+\left[1-\beta\left\langle\xi-\frac{\theta q(\theta)(1-\xi)}{r+s}\right\rangle\right] C(h)=\frac{(1-\beta)[p+f(h)-z]-\beta \theta \gamma}{r+s} .
$$

The evolution of unemployment over time is given by

$$
\dot{u}=s(1-u)-\theta q(\theta) u \text {. }
$$

In the steady-state, the unemployment rate is determined by

$$
u=\frac{s}{s+\theta q(\theta)} .
$$

The model is recursive. Under the assumptions of production and cost functions, equation (7) gives the unique equilibrium level of training $\tilde{h}$. With knowledge of $\tilde{h}$, the job creation condition (9) gives the solution for labor market tightness $\tilde{\theta}$. And finally, with $\tilde{\theta}$, (10) gives equilibrium unemployment. 


\subsection{The Social Planner's Problem}

In order to consider the efficient allocation in this economy, I analyze the social planner's problem. The efficient allocation maximizes the output of the economy subject to search frictions. The social welfare function used by the social planner is

$$
\Omega=\int_{t=0}^{\infty} e^{-r t}[y+u z-\theta u \gamma-\theta q(\theta) u C(h)] d t,
$$

where $y$ is average output per worker. The first and second terms of the bracket are total output in the economy. The third and fourth terms capture total cost: vacancy costs for firms $\theta u \gamma$ and training costs $\theta q(\theta) u C(h)$.

When the social planner chooses $\theta$ and $h$, he has to obey the evolution of unemployment given by

$$
\dot{u}=s(1-u)-\theta q(\theta) u,
$$

as well as the evolution of average output $y$ is given by

$$
\dot{y}=\theta q(\theta) u[p+f(h)]-s y .
$$

The socially efficient pair $\theta$ and $h$ maximizes (11) subject to (12) and (13). ${ }^{4}$ In addition to (12) and (13), the optimal pair satisfies the following condition

$$
\begin{aligned}
& 0=-e^{-r t}\left(u \gamma+[\theta q(\theta)]^{\prime} u C(h)\right)-\lambda[\theta q(\theta)]^{\prime} u+\mu[\theta q(\theta)]^{\prime} u[p+f(h)], \\
& 0=e^{-r t}\left(-\theta q(\theta) u C^{\prime}(h)\right)+\mu \theta q(\theta) u f^{\prime}(h), \\
& 0=e^{-r t}-\mu s+\dot{\mu}, \\
& 0=e^{-r t}(z-\theta \gamma-\theta q(\theta) C(h))+\lambda[-s-\theta q(\theta)]+\mu \theta q(\theta)[p+f(h)]+\dot{\lambda},
\end{aligned}
$$

where $\lambda$ and $\mu$ are co-state variables. The above optimal conditions yield the following two equations that uniquely determine the socially efficient $\theta$ and $h$ :

$$
\frac{\gamma}{q(\theta)}+C(h)[1-\eta(\theta)]=\frac{(p+f(h)-z)[1-\eta(\theta)]-\gamma[\theta \eta(\theta)]}{r+s},
$$

and

$$
f^{\prime}(h)=(r+s) C^{\prime}(h),
$$

where $\eta(\theta)$ is the negative of the elasticity of $q(\theta)$, and it is a number between 0 and 1 .

\footnotetext{
${ }^{4} \mathrm{I}$ am looking for a steady-state solution and therefore suppress time dependence.
} 


\subsection{Efficiency}

Now I study whether the decentralized economy could achieve efficiency by comparing social optimal conditions (14) and (15) with the decentralized equilibrium conditions (9) and (7). If the training costs are not sunk when a firm and a worker negotiate an initial wage, i.e., $\xi=1,(7)$ and (15) are identical. Thus, the training level in the decentralized economy is efficient. Setting $\xi=1$, the job creation condition in the decentralized economy (9) becomes

$$
\frac{\gamma}{q(\theta)}+[1-\beta] C(h)=\frac{(1-\beta)[p+f(h)-z]-\beta \theta \gamma}{r+s} .
$$

Comparing (14) with the above condition, it is easy to see that the two are identical if and only if $\beta=\eta$, which is the Hosios condition. This result is summarized in the following proposition.

Proposition 1 When $\xi=1$, the level of training is efficient in the decentralized economy. Furthermore, the decentralized economy is efficient if and only if $\beta=\eta$.

Setting $\xi=1$ implies that wages are bargained before the training cost is incurred. Thus, at the time of the initial wage determination, the training cost is not sunk. This prevents a firm from suffering a hold-up problem on its training costs, delivering the efficient level of training. In this case, the Hosios condition delivers efficiency in the decentralized economy. This result is basically the same as the one obtained in Cheron (2005) except that there is an endogenously determined training level introduced in my model. One may view the model of Cheron (2005) as a special case of my model where the training level is fixed.

Next, I consider the case of $\xi<1$. From (7) and (15), it is straightforward to show that the optimal training level in the decentralized economy is equal to or less than the efficient training level. $\xi<1$ implies that wages are bargained after the training costs are incurred, i.e., the costs are completely or partially sunk at the time of wage determination. Since not all of the training costs are not shared with the worker, this leads to underinvestment in the decentralized economy. This inefficiency can only be prevented by removing all the bargaining power from the worker. Thus, if I set $\beta=0$, (7) will be identical to (15) and thus the level of training in the decentralized economy is efficient. Let $h^{*}$ denote the efficient training level. Then, the job creation condition in the decentralized economy 
becomes

$$
\frac{\gamma}{q\left(\theta_{0}\right)}=\frac{\left[p+f\left(h^{*}\right)-z-(r+s) C\left(h^{*}\right)\right]}{r+s},
$$

where $\theta_{0}$ is the equilibrium labor market tightness in the the decentralized economy when $\beta=0$. Given the efficient training level $h^{*}$, the efficient labor market tightness $\theta^{*}$ can be obtained from (14). Then, it is easy to see that $\theta^{*}<\theta_{0}$, implying the unemployment rate in the decentralized economy is lower than the efficient unemployment rate. The intuition is as follows. When $\xi<1$, there is contractual incompleteness that creates a hold-up problem for a firm's investment in training. This can be prevented by removing all the bargaining power from the workers. However, this, in turn, depresses wages and creates excessive entry of firms, leading to inefficient equilibrium unemployment rate. This result is summarized in the following proposition.

Proposition 2 When $\xi<1$, the optimal training level in the decentralized economy is equal to or less than the efficient level. When $\beta=0$, the training level in the decentralized economy achieves efficiency, but the decentralized equilibrium can never be efficient.

This result is similar to the one obtained in Acemoglu and Shimer (1999) that study the efficiency of the search and matching model under the presence of match-specific investments. They demonstrate that there will be inefficiency as long as investment costs are sunk, and inefficiency can only be prevented by removing all the bargaining power from the worker. While a firm makes ex ante investments before matching with a worker in Acemoglu and Shimer (1999), in my model a firm decides the level of investments after matching with a worker. Thus, this study shows that when investment costs are sunk, the timing of investments does not play an important role in this finding.

\section{Conclusion}

Analyzing the efficiency properties of the search and matching model is important not only a theoretically point of view but also in quantitative studies where the Hosios condition is sometimes used. This paper studies the efficiency of the search and matching model with training costs. I introduce productivity enhancing firm-specific skill training into the search and matching model of Pissarides (2000). I demonstrate that while the decentralized economy can be efficient if training costs are not sunk at the time of wage determination, 
the decentralized economy is not efficient due to a hold-up problem if training costs are sunk. 


\section{References}

[1] Acemoglu, D., and R. Shimer (1999), "Holdups and Efficiency with Search Frictions," International Economic Review 40, 827-49.

[2] Boone, J., and R. A. de Mooij (2003), "Tax Policy in a Matching Model with Training," Oxford Economic Papers, 55, 121-147.

[3] Cheron, A. (2005), "Efficient v.s. Equilibrium Unemployment with Match-Specific Costs," Economics Letters 88, 176-783.

[4] Grout, P. A. (1984) "Investment and Wages in the Absence of Binding Contracts: A Nash Bargaining Approach," Econometrica 52, 449-460.

[5] Higashi, Y. (2002), "Firm Specific Human Capital and Unemployment in a Growing Economy," Japan and the World Economy 14, 35-44.

[6] Hosios, A. (1990), "On the Efficiency of Matching and Related Models of Search and Unemployment," Review of Economic Studies 57, 279-298.

[7] Hungerbuhler, M. (2007), "Tax Progression and Training in a Matching Framework," Labour Economics 14, 185-200.

[8] Malcomson, J. (1997), "Contracts, Hold-Up, and Labor Markets," Journal of Economic Literature 35, 1916-1957.

[9] Miyamoto, H., and Y. Shirai (2006), "Job Flows And Unemployment In An Equilibrium Unemployment Model With Firm-Specific Skill Training," The Japanese Economic Review, 57, 547-561.

[10] Mortensen, D. T. (2000), "Equilibrium Unemployment with Wage Posting: BurdettMortensen Meet Pissarides". in H. Bunzel, B.J. Christiansen, P. Jensen, N.M. Kiefer and D.T. Mortensen, eds., Panel Data and Structural Labor Market Models, Amsterdam: Elsevier, pp. 281-292.

[11] Pissarides, C. A. (2000) Equilibrium Unemployment Theory 2ed, Cambridge: MIT Press. 
[12] Pissarides, C. A. (2009) "The Unemployment Volatility Puzzle: Is Wage Stickiness the Answer?," Econometrica 77, 1339-1369.

[13] Shintoyo, N. (2008), "Creation of Jobs and Firm-Sponsored Training in a Matching Model of Unemployment," Journal of Economics (Zeitschrift fur Nationalokonomie), 93, 145-176.

[14] Silva, J. I., and M. Toledo (2009a), "Labor Turnover Costs and the Cyclical Behavior of Vacancies and Unemployment," Macroeconomic Dynamics 13, 76-96.

[15] Silva, J. I., and M. Toledo (2009b), "The Unemployment Volatility Puzzle: The Role of Matching Costs Revisited," MPRA Paper No. 15695.

[16] Williamson, O. E. (1975) Markets and Hierarchy, New York: Free Press. 